\title{
Endoscopic and Histologic Diagnosis of Upper Gastrointestinal Lesions, Experience in a Port City of Bangladesh.
}

Sk Md Jaynul Islam ${ }^{1 *}$

A S M Mostaque Ahmed ${ }^{2}$

M Shahab Uddin Ahamad ${ }^{3}$

SAMMA Hafiz ${ }^{4}$

\author{
Department of Pathology \\ Navy Hospital \\ Chittagong, Bangladesh. \\ ${ }^{2}$ Department of Pathology \\ Chattagram Maa- O- Shishu Hospital Medical College \\ Chittagong, Bangladesh. \\ ${ }^{3}$ Department of Pathology \\ Cox's Bazar Medical College \\ Cox's Bazar, Bangladesh. \\ ${ }^{4}$ Department of Medicine \\ Combined Military Hospital \\ Chittagong, Bangladesh.
}

\section{*Correspondence to:}

Dr. (Lt Col) Sk Md Jaynul Islam Associate Professor, Pathology \&

Consultant Histopathologist

Navy Hospital

Chittagong, Bangladesh.

Mobile: +8801620898549

E-mail: islamjaynul@yahoo.com

\begin{abstract}
Background: For upper gastrointestinal tract disorders endoscopic biopsy is common procedure performed in the hospital for a variety of benign and malignant lesions. Endoscopy is incomplete without biopsy and histopathology is the gold standard for the diagnosis of endoscopically detected lesions. Methods: A prospective study was carried out at a private histopathology diagnostic center at Chittagong from October 2012 to September 2013. All the upper GIT endoscopic biopsy samples received during the period were included in the study. The endoscopy was done by a skilled endoscopist and his detail endoscopic findings were noted. After conventional tissue processing H\&E stained slides are examined under light microscope by three competent histopathologists. Results: Among total 110 upper GIT endoscopic biopsy samples 22 (20\%) were oesophageal, 73 (66.36\%) gastric and $15(13.64 \%)$ duodenal biopsies. Among oesophageal biopsies 18 $(81.82 \%)$ were histologically neoplastic of which $13(81.25 \%)$ were SCC and 03 $(18.75 \%)$ adenocarcinoma. Rest $02(9.09 \%)$ were leiomyoma. Among all the oesophageal carcinomas, $10(62.5 \%)$ were provisionally diagnosed as carcinoma by endoscopists. Among 73 endoscopic biopsies from stomach, the mean age was 54.63 yrs. On histopathology among 73 patients, adenocarcinoma-33 (45.20\%), gastric ulcer-11 (15.07\%), gastritis-15 (20.55\%) and hyperplastic polyp-14 (19.18\%). Among 33 adenocarcinoma of stomach 23 (69.69\%) were clinically diagnosed or suspected as carcinoma by the endoscopist. Among 15 duodenal biopsies 11 $(73.33 \%)$ were diagnosed histologically as hyperplastic polyp, $02(13.33 \%)$ as adenocarcinoma, 02 (13.33\%) as ulcer. Among 110 UGIT biopsies total 51 (46.36\%) were malignant. Mean age 59.49 yrs ranges from 22 Yrs to 82 Yrs. M:F ratio is 1.4:1. Among all $33(64.7 \%)$ were gastric carcinoma, 16 (31.37\%) oesophageal carcinoma and $02(3.92 \%)$ duodenal carcinoma. Among 51, 35 (68.63\%) were clinically diagnosed or suspected as carcinoma by endoscopist. No clinical information was available in $03(5.88 \%)$ cases and rest $13(25.49 \%)$ cases were clinically diagnosed as non neoplastic conditions by the endoscopist. Conclusion: Endoscopy followed by histopathological examination play important role for diagnosis and management of UGIT lesions.
\end{abstract}

Key words: Upper Gastrointestinal lesions; Endoscopic Biopsy; Histopathology.

\section{INTRODUCTION}

Upper Gastrointestinal tract disorders are one of the most commonly encountered problems in clinical practice with a high degree of morbidity and mortality and endoscopic biopsy is common procedure performed in the hospital for a variety of benign and malignant lesions ${ }^{1}$. Upper gastrointestinal endoscopy is regarded as the investigation of choice in patients with upper gastrointestinal disorders which often present with dyspepsia ${ }^{2}$. Endoscopic examination and biopsy is a convenient procedure for accurate objective assessment of patients with symptoms of gastrointestinal tract. Endoscopy is incomplete without biopsy and histopathology is the gold standard for the diagnosis of endoscopically detected lesions ${ }^{3}$. 
The esophagus and stomach can be sited for a wide variety of infections, inflammatory disorders, vascular disorders, mechanical conditions, toxic and physical reactions, including radiation injury and neoplasm ${ }^{4}$. The prevalence of Helicobacter pylori (H. pylori) infection varies markedly in different Asian countries. The prevalence rates in developing Asian countries such as Bangladesh, India, Thailand and Vietnam have been reported to be especially high at $92 \%, 81 \%, 74 \%$ and $75 \%$ respectively ${ }^{5-8}$. Helicobacter pylori (H. pylori), infection has been linked to acute and chronic gastritis, non-ulcer-dyspepsia, peptic ulcer, gastric adenocarcinoma and gastric non-Hodgkin's lymphoma of mucosa-associated lymphoid tissue (MALT) ${ }^{9}$.

At Chittagong, a port city of Bangladesh this study was carried out to correlate the clinical impression of endoscopists during upper GIT endoscopy with histopathological confirmation.

\section{MATERIALS \& METHODS}

A prospective study was carried out at a private histopathology diagnostic center at Chittagong during the period of 01 year from October 2012 to September 2013. All the upper GIT endoscopic biopsy samples received during the period were included in the study. The endoscopy was done by a skilled endoscopist and his detail clinical findings during the endoscopy procedure noted in a pre designed sheet were used as study material. All the biopsy samples were counted for fragments of tissue, put in a filter paper shocked with normal saline and immediately immersed in $10 \%$ formalin. After conventional tissue processing routine $\mathrm{H} \& \mathrm{E}$ staining is performed. The H\&E stained slides were examined under light microscope by three competent histopathologists.

\section{RESULTS}

During the stipulated period total 110 upper GIT endoscopic biopsy samples were received. Among all 58 were male and 52 were female with the ratio $\mathrm{M}: \mathrm{F}=1.12: 1$. The age of the study population ranges from minimum 18 to maximum 86 with the mean age 54.46 Yrs. The age distributions in different decades are shown in Figure 1.

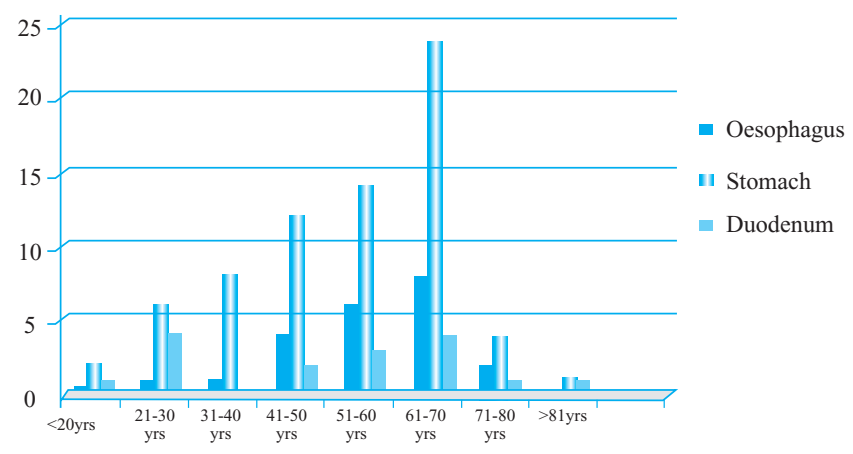

Figure 1: Age distribution of site wise upper endoscopy biopsy ( $\mathrm{n}=110)$.

Among 110 cases $22(20 \%)$ were oesophageal biopsy, 73 (66.36\%) gastric biopsy and 15 (13.64\%) were duodenal biopsy (Figure 2). Among 22 oesophageal biopsies mean age was 57.32 Yrs. Endoscopist reported $04(18.18 \%)$ as growth, 12 $(54.55 \%)$ as carcinoma, $01(4.55 \%)$ as candidiasis, 01 (4.55) as

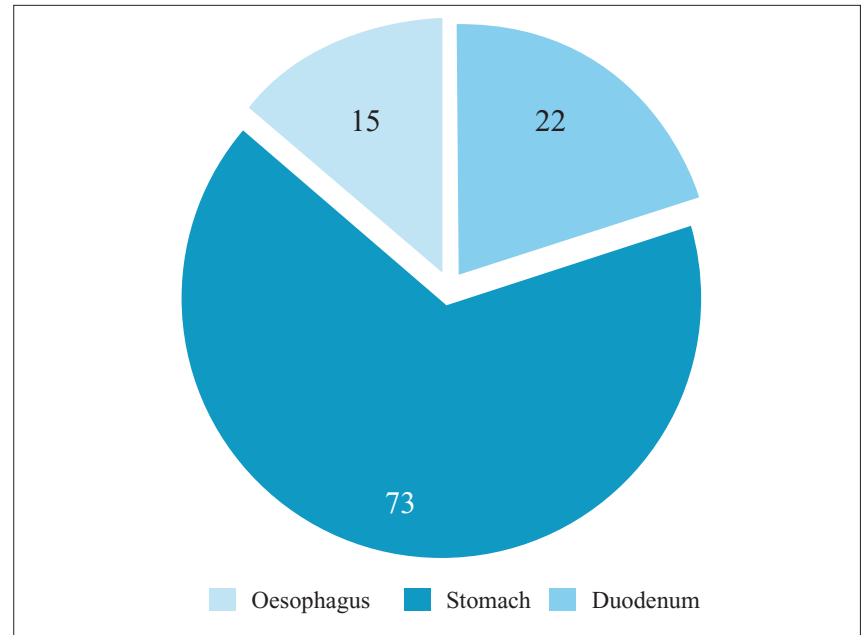

Figure 2 : Site distribution of the cases $(\mathrm{n}=110)$.

oesophagitis and $01(4.55 \%)$ as polyp while no history or endoscopist's comment was available in $03(13.63 \%)$ cases (Table 1).

Table 1 : Distribution of oesophageal lesions $(n=22)$ :

\begin{tabular}{|c|c|c|c|}
\hline \multicolumn{2}{|c|}{ Endoscopic Diagnosis $(\mathrm{n}=22)$} & \multicolumn{2}{|c|}{ Histologic Diagnosis $(\mathrm{n}=22)$} \\
\hline Carcinoma & $12(54.55 \%)$ & Neoplastic lesions & $18(81.82 \%)$ \\
\hline & & Sq Cell Carcinoma -13 & \\
\hline & & Adenocarcinoma- 3 & \\
\hline & & Leiomyoma- 2 & \\
\hline Growth & $4(18.18 \%)$ & Oesophagitis & $4(18.18 \%)$ \\
\hline Oesophagitis & $1(4.55 \%)$ & & \\
\hline Candidiasis & $1(4.55 \%)$ & & \\
\hline Polyp & $1(4.55 \%)$ & & \\
\hline Not available & $3(13.63 \%)$ & & \\
\hline Total & $22(100 \%)$ & Total & $22(100 \%)$ \\
\hline
\end{tabular}

Among all the oesophageal biopsies histologically 18 (81.82\%) were diagnosed as neoplastic lesion of which $16(72.2 \%)$ were malignant neoplasm and $02(9.09 \%)$ were benign smooth muscle tumour, leiomyoma. Among 16 malignant tumours 13 $(81.25 \%)$ were squamous cell carcinoma and $03(18.75 \%)$ were adenocarcinoma. All the non neoplastic lesions 4 (18.18\%) are histologically diagnosed as oesophagitis. Among all the histologically confirmed malignant tumour of oesophagus, 10 $(62.5 \%)$ were provisionally diagnosed as carcinoma by endoscopists. While among 12 clinically suspected malignant lesions, $10(83.33 \%)$ were histologically confirmed as malignant. The mean age of malignant oesophageal tumour was 56.56 Yrs.

Among 73 endoscopic biopsies from stomach, the mean age was 54.63 yrs. The provisional diagnoses by endoscopists are gastritis-13 (17.81\%), gastric ulcer- $16(21.92 \%)$ of which 02 were giant ulcer, polyp- $13(17.81 \%)$, ulcer/carcinoma-08 (10.96\%), carcinoma- 20 (27.39\%), growth- 02 (2.73\%) and no clinical impression was available in $01(1.37 \%)$ case (Table 2). 
Table 2 : Distribution of Gastric Lesions $(n=73)$

\begin{tabular}{llll} 
Endoscopic Diagnosis $(\mathrm{n}=73)$ & \multicolumn{2}{c}{ Histologic Diagnosis $(\mathrm{n}=73)$} \\
Gastritis & $13(17.81 \%)$ & Gastritis & $15(20.55 \%)$ \\
Gastric Ulcer & $16(21.92 \%)$ & Gastric Ulcer & $11(15.07 \%)$ \\
Polyp & $13(17.81 \%)$ & Hyperplastic polyp & $14(19.18 \%)$ \\
Ulcer/?Carcinoma & $08(10.96 \%)$ & Adenocarcinoma & $33(45.20 \%)$ \\
Carcinoma & $20(27.39 \%)$ & & \\
Growth & $02(2.73 \%)$ & & \\
No Impression & $1(1.37 \%)$ & & $73(100 \%)$ \\
Total & $73(100 \%)$ & Total \\
\hline
\end{tabular}

While on histopathology $33(45.20 \%)$ were diagnosed as adenocarcinoma of different grades. Other diagnoses are gastric ulcer- 11 (15.07\%), gastritis of different grades- 15 (20.55\%) and hyperplastic polyp- 14 (19.18\%). Among 20 clinically diagnosed carcinoma, 17 (85\%) were histologically confirmed as malignant while among 08 clinically suspected ulcer/?cacinoma cases 06 (75\%) were histologically confirmed as malignant. In contrast among 33 histologically confirmed adenocarcinoma cases $23(69.69 \%)$ were clinically diagnosed or suspected as carcinoma by the endoscopist. The mean age of gastric malignant tumour was 60.12 Yrs.

Among 15 duodenal biopsies the mean age was $49.47 \mathrm{yrs}$. Among all $09(60 \%)$ were clinically diagnosed by endoscopist as polyp, $02(13.33 \%)$ as malignant, $02(13.33 \%)$ as ulcer, 01 $(6.66 \%)$ as growth and $01(6.66 \%)$ as Brunn's gland (Table 3$)$.

Table 3 : Distribution of Duodenal Lesions

\section{Endoscopic Diagnosis $(\mathrm{n}=15)$ Histologic Diagnosis $(\mathrm{n}=15)$}

$\begin{array}{llll}\text { Hyperplastic Polyp } & 09(60 \%) & \text { Hyperplastic polyp } & 11(73.33 \%) \\ \text { Ulcer } & 02(13.33 \%) & \text { Ulcer } & 02(13.33 \%) \\ \text { Brunn's Gland } & 01(6.66 \%) & \text { Adenocarcinoma } & 02(13.33 \%) \\ \text { Growth } & 01(6.66 \%) & & \\ \text { Malignant } & 02(13.33 \%) & & \\ \text { Total } & 15(100 \%) & \text { Total } & 15(100 \%)\end{array}$

On histopathological examination all clinically suspected malignant cases were confirmed as adenocarcinoma and all clinically detected duodenal ulcers were also confirmed histologically as benign ulcer. Rest $11(73.33 \%)$ were diagnosed histologically as hyperplastic polyp. The mean age of duodenal malignant tumour was 72.5 Yrs.

Among 110 upper gastrointestinal biopsies 51 (46.36\%) were malignant. Mean age of cancer affected persons was 59.49 yrs with minimum 22 yrs to maximum 82 Yrs. Male and female ratio is $1.4: 1$. Among all $33(64.7 \%)$ were gastric carcinoma, 16 (31.37\%) were oesophageal carcinoma and 02 (3.92\%) duodenal carcinoma. Among 51, 35 (68.63\%) were clinically diagnosed or suspected as carcinoma by endoscopist. No clinical information was found in $03(5.88 \%)$ cases and rest 13 $(25.49 \%)$ cases were diagnosed as non neoplastic conditions by the endoscopist.

\section{DISCUSSION}

Good clinical and endoscopy information is a fundamental part of "adequacy" and this strongly affects how a biopsy should be read. However, the precise diagnosis becomes more certain on histopathological examination. The most common indications for gastric biopsy are; to detect various types of gastritis along with evidence of Helicobacter pylori status, gastric ulcers and different tumours ${ }^{10}$.

Malignant tumours of the upper gastrointestinal tract (oesophagus and stomach) account for 13,300 deaths and approximately 16,600 new cases each year in the $\mathrm{UK}^{11}$. These tumours usually have a long natural history and may present at a fairly advanced stage. Nevertheless, patients with these tumours exhibit important alarm symptoms, for example, dysphagia, dyspepsia, chronic gastrointestinal bleeding, progressive unintentional weight loss, progressive difficulty in swallowing, persistent vomiting, iron deficiency anaemia or epigastric mass that warrant further clinical investigations.

In our study among 110 upper GIT endoscopic biopsies Male:Female ratio was 1.12:1 with the mean age 54.46 yrs. Most of the biopsies were from sixth decade. While Krishnappa Rashmi et $\mathrm{al}^{1}$ got the predominance of upper GIT disease in $5^{\text {th }}$ decade. Other workers also got male predominance ${ }^{12-13}$. Among 110 cases stomach was the commonest $(66.36 \%)$ site of UGIT endoscopic biopsy followed by oesophagus and duodenum. The findings correlate with other findings ${ }^{1-2,14}$.

In our study among 22 oesophageal biopsies, 18 (81.82\%) were neoplastic lesions which includes $16(72.2 \%)$ malignant and 2 (9.09\%) benign. Among the malignant tumours $13(81.25 \%)$ were squamous cell carcinoma and 03 (18.75\%) were adenocarcinoma. While Rashmi $\mathrm{K}$ et al in their study got predominantly non neoplastic oesophagitis and only $44 \%$ were neoplastic lesions, though all of their neoplastic oesophageal lesions were malignant lesions and those all were squamous cell carcinoma ${ }^{1}$. In our cases we got $18.75 \%$ adenocarcinoma in oesophagus. In contrast Qureshi N A et al found 70.2\% adenocarcinoma among all the oesophageal cancers while squamous cell carcinomas were $23.1 \%$, signet cell carcinoma $1.35 \%$, anaplastic cancers $2.70 \%$ and undifferentiated tumours with neuro-endocrine differentiation $(2.70 \%)^{13}$. In our study among all the histologically confirmed malignant tumour of oesophagus, $10(62.5 \%)$ were clinically diagnosed as carcinoma by endoscopists. While Kazi J I et al got $100 \%$ correlation in oesophageal biopsy with histologic findings in oesophageal malignancy ${ }^{14}$.

In our study among 73 endoscopic gastric biopsies $45.20 \%$ were diagnosed as malignant and all were adenocarcinoma of different grades. While Rashmi K et al found $27.94 \%$ malignant lesions among 68 gastric endoscopic biopsies and all were adenocarcinoma; Bhatty et al got gastric carcinoma in only $1.9 \%$ cases of a large series of 1076 upper GIT endoscopy biopsies $^{1,15}$. Their predominant cases were gastritis $(83.4 \%)$. In our case we got gastritis in only $20.55 \%$ of all gastric endoscopy biopsies. In our study among the histologically confirmed adenocarcinoma cases had concordance of $69.69 \%$ with clinical diagnoses by endoscopist while Kazi JI et al found $88.8 \%$ concordance for gastric carcinoma ${ }^{14}$. 
Mean age of gastric carcinoma was 60.12 Yrs. While Islam SMJ found mean age 43.14 Yrs among 625 gastric adenocarcinoma $\operatorname{cases}^{16}$. In our study duodenal hyperplastic polyps were the commonest pathology among the duodenal biopsies both endoscopically as well as histopathologically. Duodenal malignancies were found in $13.33 \%$ cases by both endoscopist and histopathologist while Kazi JI et al found duodenitis as the commonest pathology $(56.85 \%)^{14}$. They have not got any duodenal malignancy among 146 duodenal biopsies.

In our study among all the upper GIT endoscopic biopsies, $46.36 \%$ were malignant. Mean age of the malignant cases was 59.49 yrs and males were affected more. The most commonly affected site of malignant lesions was stomach (64.7\%). Rashmi K et al also got highest incidence in $4^{\text {th }}$ and $5^{\text {th }}$ decade with male predominance ${ }^{1}$. But in their study, oesophagus was the commonest site for malignant lesion.
Regarding concordance with endoscopic diagnoses, in our study $68.63 \%$ of histologically confirmed malignant cases were clinically diagnosed or suspected by the endoscopist while Kazi JI et al found $88.8 \%$ to $100 \%$ concordance of endoscopists and histopathologists depending on site of the malignant lesion. ${ }^{14}$

\section{CONCLUSION}

Common site of UGIT lesions is stomach. In Chittagong region incidence of gastric carcinoma is more among UGIT malignancy. Endoscopy followed by histopathological examination play important role for diagnosis and management of UGIT lesions.

\section{DISCLOSURE}

All the authors declared no competing interest.

\section{REFERENCES}

1. Rashmi K, Horakerappa MS, Karar A, Mangala G. A Study on Histopathological Spectrum of Upper Gastrointestinal Tract Endoscopic Biopsies. Int J Med Res Health Sci. 2013;2 (3):418-424. DOI: 10.5958/j.2319-5886.2.3.073.

2. Mustapha SK, Bolori MT, Ajayi NA, Nggada HA, Pindiga UH, Gashau W, Khalil MIA. Endoscopic Findings and The Frequency of Helicobacter Pylori Among Dyspeptic Patients in North-Eastern Nigeria. Highland Medical Research Journal. 2007; 5: 78-81.

3. Pailoor K, Sarpangala M K, Naik RCN. Histopathological diagnosis of gastric biopsies in correlation with endoscopy - a study in a tertiary care center. Adv Lab Med Int. 2013; 3(2): 22-31.

4. Rosai J In: Rosai and Ackerman’s surgical pathology. 9th ed. St. Louis: Mosby; 2004. pp 648-651.

5. Ahmad MM, Rahman M, Rumi AK, Islam S, Huq F, Chowdhury MF, Jinnah F, Morshed MG, Hassan MS, Khan AK, Hasan M. Prevalence of Helicobacter pylori in asymptomatic population - a pilot serological study in Bangladesh. J Epidemiol 1997; 7:251-4.

6. Ramakrishna BS. Helicobacter pylori infection in India: the case against eradication. Indian J Gastroenterol. 2006; 25: 25-28.

7. Perez-perez GI, Taylor DN, Bodhidatta L, Wongsrichanalai J, Baze WB,. Dunn BE, Echeverria PD, Blaser MJ. Seroprevalence of Helicobacter pylori infections in Thailand. J Infect Dis. 1990; 161: 1237-1241.

8. Hoang TT, Bengtsson C, Phung DC, Sorberg M, Granstrom M. Seroprevalence of Helicobacter pylori infection in urban and rural Vietnam. Clin Diagn Lab Immunol. 2005; 12: 81-85.

9. Kumar A, Bansal R, Pathak VP, Kishore S, Karya PK. Histopathological changes in gastric mucosa colonized by H. pylori. Indian Journal of Pathology and Microbiology. 2006; 49: 352-356.

10. Dominis M, Dzebro S, Gasparov S, Buljevac M, Coli?-Cvrlje V, Bani? M, Katici? M. Morphology of gastritis and Helicobacter pylori infection. Lijec Vjesn. 2002; 124: 36 - 42.

11. Cancer Research UK: Information resource center 2004.

12. Rabbani A. Experience with Endoscopy at Bin Jalawi Hospital K.S.A. J Ayub Med Coll Abottabad. 2005;17:37-39.

13. Qureshi NA, Hallissey MT, Fielding JW. Outcome of Index Upper Gastrointestinal Endoscopy in Patients Presenting with Dysphagia in a Tertiary Care Hospital-A 10 Years Review. BMC Gastroenterology. 2007, 7:43 doi:10.1186/1471-230X-7-43.

14. Kazi J I, Alam SM, Kazi AM, Anwar A, Shamsi Z. Correlation of Endoscopic and Histologic Diagnosis in Upper Gastrointestinal lesions. JPMA. 1990;40(12):281-283.

15. Bhatty AS, Shaikh NA, Zahir N, Akhter SS, Vaswani AS, Manzoor H. Histopathologic Spectrum of Upper Gastrointestinal Endoscopies. Medical Channel. 2009;15(4):11-14.

16. Islam SMJ, Ali SM, Ahmed S, Afroz QD, Chowdhury R, Huda M. Histopathologic Pattern of Gastric Carcinoma in Bangladesh. JAFMC Bangladesh. 2009;15(1):21-24. 